Disclosure of Interests: None declared

DOI: 10.1136/annrheumdis-2020-eular.5763

\section{THU0031 \\ ABATACEPT ALTERS THE FREQUENCY OF IMMUNOREGULATORY AND EFFECTOR T CELL SUBPOPULATIONS IN RHEUMATOID ARTHRITIS}

B. Dreo $^{1}$, B. Prietl ${ }^{2,3}$, S. Kofler ${ }^{3}$, H. Sourij ${ }^{2,3}$, A. Lackner ${ }^{1}$, F. Moazedi-Fürst ${ }^{1}$, M. D'orazio ${ }^{1}$, M. Stradner ${ }^{1}$, W. Graninger ${ }^{1}$, H. P. Brezinschek ${ }^{1}{ }^{1}$ Medical University of Graz, Division of Rheumatology and Immunology, Graz, Austria; ${ }^{2} \mathrm{CBmed} \mathrm{GmbH}$ - Center for Biomarker Research in Medicine, Graz, Austria; ${ }^{3}$ Medical University of Graz, Division of Endocrinology and Diabetology, Graz, Austria

Background: Under physiological conditions, $\mathrm{T}$ regulatory cells (Tregs) are responsible for the downregulation of the immune response. In autoimmune diseases, such as rheumatoid arthritis (RA), auto-inflammation is driven by an imbalance of activation and downregulation of immunological pathways. Thus, treatment plans for autoimmune diseases often involve the enhancement of immunoregulatory pathways by administering inhibitors of costimulation, i.e. CTLA-4-Ig (abatacept, ABA). ABA binds specifically to CD80 and CD86 on antigen presenting cells (APC). Consequently, T cell activation via the CD28 receptor is blocked. Previous studies have demonstrated surprising effects of abatacept on Tregs, specifically decreased frequency of these cells but enhancement in their function ${ }^{1}$. Whether these alterations can only be found in patients with ABA treatment, or whether they are also present in patients receiving other anti-inflammatory drugs is currently unknown.

Objectives: The aim of our research was to delineate the impact of ABA on the different subsets of effector and regulatory T cells in RA and compare these findings with patients receiving tocilizumab (TCZ) or rituximab (RTX).

Methods: Peripheral blood samples from 56 RA patients (median \pm SE; age: $60.5 \pm 1.3$ years, female ratio: 0.7 , disease duration: $17.9 \pm 2.1$ years; respectively) were drawn over a sampling period of 2 years. Freshly isolated PBMCs of RA patients were stained with fluorochrome-labelled antibodies and $T$ cell subsets were identified by flow cytometric means. $C D 3^{+} C D 4^{+} \mathrm{T}$ cells were further classified using different T cell markers (CD25, CD127, CD39, CD95). All cytometric measurements were performed using a standardized BD LSR-Fortessa platform. RA patients were compared according to their treatment with ABA, TCZ or RTX

Results: Eighteen out of 56 RA patients (32\%) received ABA, 25 patients (45\%) received $T C Z$ and 13 patients (23\%) were under CD20+ cell depletion therapy with RTX. RA patients receiving ABA displayed a significant decrease in $\mathrm{CD}^{+} \mathrm{CD} 4^{+} \mathrm{CD} 25^{+} \mathrm{CD} 127^{\mathrm{dim}}$ Tregs $(3.7 \% \pm 0.4)$ compared to patients with TCZ $(5.4 \% \pm 0.4, p=0.041)$ and patients under RTX treatment $(7.52 \% \pm 0.93, p=$ $0.026)$. CD $39^{+}$Tregs were significantly higher in RA patients treated with TCZ $(49.5 \%+3.2, p=0.000)$ or $\operatorname{RTX}(50.5 \% \pm 5.3, p=0.026)$ compared to patients receiving $\mathrm{ABA}(24.5 \% \pm 3.1)$. In addition, the frequency of $\mathrm{CD} 95^{+}$Tregs was significantly reduced in ABA patients compared to RTX patients $(59.6 \% \pm 3.1$ vs.76.7\% $\pm 3.6, p=0.014$; respectively). Interestingly, $T$ cells displaying an effector $\mathrm{T}$ cell phenotype $\left(\mathrm{CD}^{+} \mathrm{CD} 4^{+} \mathrm{CD} 25^{+/} \mathrm{CD} 127^{+}\right)$were increased in $\mathrm{ABA}$ treated patients compared to RTX treated patients $(59.6 \% \pm 3.1$ and $76.7 \% \pm 3.6, p=$ 0.002 ). Since none of our patients were a non-responder or had high disease activity, we could not analyse whether these changes are associated with treatment outcome.

Conclusion: Our data demonstrate that blockage of $\mathrm{T}$ cell stimulation via ABA leads to characteristic alterations in different regulatory and effector $T$ cells not seen in patients treated with TCZ or RTX. Further studies must clarify whether the analysis of regulatory and effector $T$ cell subpopulations before treatment initiation can be used as biomarker for treatment response.

References:

[1] Álvarez-Quiroga C, Abud-Mendoza C, Doníz-Padilla L, et al. CTLA-4-Ig therapy diminishes the frequency but enhances the function of treg cells in patients with rheumatoid arthritis. J Clin Immunol. 2011;31(4):588-595. doi: $10.1007 /$ s10875-011-9527-5

Acknowledgments: Work done in "CBmed" was funded by the Austrian Federal Government within the COMET K1 Centre Program, Land Steiermark and Land Wien.

Disclosure of Interests: None declared

DOI: 10.1136/annrheumdis-2020-eular.4894

\section{THU0032 MODIFIED PEPTIDES AS A NOVEL IMMUNOTHERAPY} FOR RHEUMATOID ARTHRITIS

E. Araklioti ${ }^{1,2}$, L. Herman ${ }^{1}$, N. Q. N. Nguyen ${ }^{1}$, R. Roohi Ahangarani ${ }^{1}$, M. Erak ${ }^{1}$, B. Lauwerys ${ }^{3}$, P. Durez ${ }^{3}$, V. Geenen ${ }^{2}$, A. Winkler ${ }^{4}$, M. Van Mechelen ${ }^{1}$, L. Vander Elst ${ }^{1}$, V. Carlier ${ }^{1} .{ }^{1}$ Imcyse SA, Liège, Belgium; ${ }^{2}$ University of Liège, GIGA,
Laboratory of Immunoendocrinology, Liège, Belgium; ${ }^{3}$ Cliniques Universitaires Saint-Luc, Department of Rheumatology, Brussels, Belgium; ${ }^{4}$ Pfizer Inc., Cambridge, United States of America

Background: Rheumatoid arthritis (RA) is a highly prevalent and severe systemic autoimmune disease associated with permanent disability and strong socio-economic burdens. Currently, there is no therapeutic treatment and RA patients rely on lifelong, costly treatments. Imcyse develops modified peptides eliciting antigen specific cytolytic CD4 T cells (cCD4+) that induce apoptosis of antigen presenting cells (APC) in a contact dependent manner. cCD4+ also induce apoptosis of autoantigen-specific bystander T-cells, activated by the same APC thus eliminating the risk of general immunosuppression. Peptides consist of $\mathrm{MHC}$ class II T cell epitopes of a target autoantigen modified in their flanking region by the addition of an amino acid sequence containing a thiol-disulphide oxidoreductase active motif ${ }^{1}$.

Objectives: The goal of this study was to synthesize modified peptides from a target RA autoantigen and test their potency to generate in vitro specific and cytolytic CD4+ T cells from RA patients.

Methods: We designed modified peptides from a target RA autoantigen after in silico and in vitro assessment to identify MHC II core binding region, HLA class II binding capacities and physiochemical properties.

CD4+ T cells were purified from PBMC of a newly diagnosed seropositive RA patient and co-cultured with autologous APC in the presence of the modified peptide. The CD4+ T cells were restimulated periodically. Peptide's ability to generate specific CD4+ T cells was evaluated by flow cytometric analysis of the expression of surface activation marker CD154 (CD40L). The peptide specific CD4+ T cell lines were sorted based on their surface CD154 expression. Their pro-apoptotic activity was assessed after overnight $(\mathrm{O} / \mathrm{N})$ co-culture of CD4+ T cells with fluorescent tracer labelled autologous lymphoblastoid cells lines (LCL). Flow cytometry quantification of LCL apoptosis was measured by annexin $\mathrm{V}$ staining. MHC II restriction of CD4+ T cells was demonstrated by the addition of blocking antibodies against HLA-DR, DP or DQ molecules.

Results: CD4+ T cells were in vitro expanded after six consecutive stimulations with the peptide. We investigated their specificity by flow cytometry and showed that $69 \%$ of $\mathrm{CD} 4+\mathrm{T}$ cells that were stimulated $\mathrm{O} / \mathrm{N}$ in the presence of the peptide expressed the activation marker CD154 versus $29 \%$ of CD4+ T cells that were stimulated in its absence. These cells were sorted based on CD154 expression following specific stimulation. Cell enrichment was then assessed by flow cytometric analysis. Data showed that more than $91 \%$ (background $3 \%$ ) were peptide specific based on CD154 expression.

After co-culture of CD4+ T cells with LCL, in independent experiments, Annexin $\mathrm{V}$ binding was detected on peptide loaded LCL, ranging from $69 \%$ to $89 \%$, while when LCL were kept unloaded these values were between $30 \%$ and $55 \%$, respectively, indicating that when specifically activated, these CD4+ T cells had pro-apoptotic activity. When both the peptide and blocking antibodies against HLA-DR, DP or DQ molecules added in the co-culture the pro-apoptotic activity was inhibited by $68 \%, 20 \%$ and $25 \%$, respectively.

Conclusion: The preliminary but very promising data show that our modified peptide generates peptide-specific CD4+ T cells with lytic properties that lyse target APC in an HLA class II specific manner. Our plan is to show that these CD4+ $T$ cells can also induce apoptosis in bystander $T$ cells and to further validate our results in additional RA donors.

\section{References:}

[1] Carlier, V. A., Vanderelst, L., Janssens, W. \& Jacquemin, M. G. Increased Synapse Formation Obtained by T Cell Epitopes Containing a CxxC Motif in Flanking Residues Convert CD4 + T Cells into Cytolytic Effectors. 7, (2012).

Disclosure of Interests: Eleni Araklioti Grant/research support from: This work was supported by Pfizer Inc. and by Walloon Region, Ludivine Herman Grant/ research support from: This work was supported by Pfizer Inc. and by Walloon Region, Ngoc Quynh Nhu Nguyen Grant/research support from: This work was supported by Pfizer Inc. and by Walloon Region, Roxana Roohi Ahangarani Grant/research support from: This work was supported by Pfizer Inc. and by WalIoon Region, Milos Erak Grant/research support from: This work was supported by Pfizer Inc. and by Walloon Region, Bernard Lauwerys: None declared, Patrick Durez Speakers bureau: AbbVie, Bristol-Myers Squibb, Celltrion, Eli Lilly, Pfizer, Sanofi, Vincent Geenen: None declared, Aaron Winkler Shareholder of: Shareholder of Pfizer, Inc, Employee of: Full time employee of Pfizer, Inc, Marcelle Van Mechelen Grant/research support from: This work was supported by Pfizer Inc. and by Walloon Region, Luc Vander Elst Grant/research support from: This work was supported by Pfizer Inc. and by Walloon Region, Vincent Carlier Grant/ research support from: This work was supported by Pfizer Inc. and by Walloon Region

DOI: 10.1136/annrheumdis-2020-eular-2714 